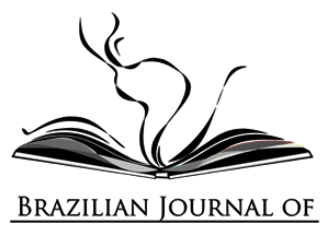

\title{
LUGARES DE MEMÓRIA DAS DITADURAS CIVIS-MILITARES LATINO-AMERICANAS, ARQUITETURA E INSCRIÇÕES DE SENTIDO
}

\author{
LUGARES DE MEMORIA DE LAS DICTADURAS CÍVICO-MILITARES EN \\ LATINOAMÉRICA, ARQUITECTURA E INSCRIPCIONES DE SENTIDO
}

PLACES OF MEMORY OF CIVIL-MILITARY DICTATORSHIPS IN LATIN

AMERICA, ARCHITECTURE AND SENSE INSCRIPTIONS

Caio Vargas Jatene ${ }^{7}$

Universidade de São Paulo, Brasil

Luiz de Lucca Neto ${ }^{2}$ iD

Universidade de São Paulo, Brasil

\begin{abstract}
Resumo: O objetivo do presente trabalho é analisar, em perspectiva comparada, três lugares de memória latino-americanos, criados no âmbito de medidas de Justiça de Transição, para construção crítica da memória traumática pós-ditaduras civis-militares. São eles: o Espacio Memoria y Derechos Humanos (Ex-ESMA - Escuela de Mecánica de la Armada) em Buenos Aires, Argentina; o Memorial da Resistência de São Paulo, Brasil e o Museo de la Memoria y los Derechos Humanos, situado em Santiago, Chile. A análise comparativa dos elementos históricos e arquitetônicos, bem como dos projetos de memorialização, permitiu concluir, preliminarmente, a presença de formas distintas de inscrições de sentido por parte da sociedade e trajetórias diferentes de preservação, consoante aos limites e às conjunturas internas de cada país.
\end{abstract}

Palavras-chave: Lugares de Memória; Ditaduras Civis-Militares; Justiça de Transição; Arquitetura; Patrimônio.

Resumen: El objetivo del presente trabajo es analizar, en una perspectiva comparativa, tres lugares de memoria latinoamericanos, creados al amparo de las medidas de Justicia de Transición, para la construcción

\footnotetext{
${ }^{1}$ Mestrando do Programa de Pós-Graduação em Ciência da Informação da Escola de Comunicações e Artes da Universidade de São Paulo (PPGCI-ECA-USP), bolsista CAPES. E-mail: caio.jatene@usp.br.

2 Mestrando do Programa de Pós-Graduação em Arquitetura e Urbanismo da Faculdade de Arquitetura e Urbanismo da Universidade de São Paulo (PPGAU-FAU-USP), E-mail: luiz.lucca.neto@usp.br
} 
crítica de la memoria traumática después de las dictaduras civil-militares. Ellos son: Espacio Memoria y Derechos Humanos (ex ESMA - Escuela de Mecánica de la Armada) en Buenos Aires, Argentina; el Memorial da Resistência de São Paulo, Brasil, y el Museo de la Memoria y los Derechos Humanos, ubicado en Santiago, Chile. El análisis comparativo de los elementos históricos y arquitectónicos, así como los proyectos de memorialización permiten concluir, preliminarmente, la presencia de distintas formas de inscripciones de significado por parte de la sociedad y diferentes trayectorias de preservación, dependiendo de los límites y circunstancias internas de cada país.

Palabras clave: Lugares de Memoria; Dictaduras Civiles-Militares; Justicia de Transición; Arquitectura; Patrimonio.

Abstract: The goal of this paper is to analyze, through a comparative perspective, three Latin American places of memory created in the context of Transitional Justice measures, for the critical construction of the traumatic memory after Civil-Military Dictatorships. They are: the Espacio Memoria y Derechos Humanos (former ESMA - Escuela de Mecánica de la Armada) in Buenos Aires, Argentina; the Memorial da Resistência de São Paulo, in Brazil; and the Museo de la Memoria y los Derechos Humanos, located in Santiago, Chile. The comparative analysis of historical and architectural elements, as well as the memorialization projects, allow to conclude, preliminarily, the presence of different forms of sense inscriptions by the society and different trajectories of preservation, according to the limits and the internal circumstances of each country.

Keywords: Places of Memory; Civil-Military Dictatorships; Latin America; Architecture; Heritage.

DOI:10.11606/issn.1676-6288.prolam.2020.170383

Recebido em: 30/05/2020 Aprovado em: 06/12/2020 Publicado em: 30/12/2020

\section{INTRODUÇÃO}

O objetivo do presente trabalho é analisar, em perspectiva comparada, três lugares de memória das ditaduras civis-militares, instaladas na América Latina, a partir de meados do século XX. Esses dispositivos são: o Espacio Memoria y Derechos Humanos (Ex-ESMA Escuela de Mecánica de la Armada), situado em Buenos Aires, Argentina; o Memorial da Resistência, situado em São Paulo, Brasil; o Museo de la 
Memoria y los Derechos Humanos, situado em Santiago, Chile. Os três casos são lugares de memória emblemáticos, criados pós-ditaduras civis-militares no âmbito das medidas de Justiça de transição. Este trabalho parte da hipótese de que a memória pode ser transmitida por meio da patrimonialização e da arquitetura. Nesse sentido, a utilização do método histórico para investigar tais instituições permite verificar sua influência nas sociedades em que se inserem. Associado a isso, a análise dos projetos de memorialização e dos elementos arquitetônicos possibilitam averiguar como a memória é depositada e transmitida nesses locais.

Muitos documentos, vestígios materiais e provas do terrorismo de Estado foram deliberadamente apagados ao final das ditaduras e durante o início dos processos de transição nesses países latino-americanos, que emergiram dos autoritarismos militares. No entanto, com base nos testemunhos das vítimas e por iniciativa de organizações da sociedade civil, posteriormente encampadas pelos governos democráticos, foram criados lugares de memória política, hoje um dos principais suportes materiais de memória, provas das violações dos direitos humanos, bem como instrumentos de compensação simbólica das vítimas e de toda a sociedade. Disso decorre a importância de estudo e preservação desses espaços.

O conceito lugares de memória foi cunhado e desenvolvido pelo historiador Pierre Nora (1993). Segundo este autor, os lugares de memória são os loci "onde a memória se cristaliza e se refugia" (NORA, 1993, p. 7). Para ser um lugar de memória, é necessário "ter vontade de memória" (NORA, 1993, p. 22), intenção de determinados grupos em admitir um determinado local como detentor de memória coletiva. Na falta dessa intencionalidade, o local será apenas um lugar de história (NORA, 1993). A coletividade não reconhece um lugar apenas como digno de lembrança, pois nele são depositadas inscrições de sentido. Por isso, Paul Ricoeur denomina esses locais como "lugares socialmente marcados" (2018, p. 131). 
Além da intencionalidade, nos lugares de memória coexistem três aspectos simultaneamente: o material, o simbólico e o funcional (NORA, 1993). Para o filósofo Paul Ricoeur (2018), a materialização da memória está vinculada ao elogio do patrimônio, locais nos quais ancorar a memória coletiva. Ademais, Nora afirma que o objetivo fundamental de um lugar de memória é "parar o tempo" (1993, p. 22). No mesmo sentido, para Hartog (2013), os lugares são brechas temporais. Destinam-se a parar o trabalho de esquecimento (NORA, 1993). Por essa razão, os lugares podem ser tratados como veículos de memória, pois as marcas territoriais da memória são dependentes das significações conferidas pelo trabalho e pelas ações coletivas, políticas e simbólicas ou rituais (JELIN; LANGLAND, 2003).

Não obstante, é importante aplicar a concepção de Nora (1993) ao contexto latino-americano traumático pós-ditaduras civis-militares e, assim, trazer tal discussão conceitual para esse cenário específico, onde os lugares de memória podem ser utilizados como pontos de partida para uma análise mais geral das lutas por memória e das inscrições de sentido sociais sobre o passado recente, de repressão política e de terrorismos de Estado (JELIN; LANGLAND, 2003). Na América Latina, as lutas políticas por memória são traduzidas em lutas por verdade, justiça e construção crítica de uma memória emancipatória e conscientizadora. Assim, o estabelecimento dos lugares resulta da luta política, cujas forças sociais adversárias demandam a institucionalização de marcas de memória ou o apagamento dessas marcas (JELIN, 2002).

Como a ativação da memória ocorre em ambientes de confrontação política, tanto na Argentina, no Brasil e no Chile, alguns grupos conseguiram, em maior ou menor gradação, marcar os espaços analisados com um certo conjunto de significações. Nesses espaços, as batalhas por memória foram vencidas e representaram algum tipo de avanço. Tanto os atores da construção da memória, quanto os lugares, estão inscritos em um devir histórico-temporal que se transforma em diferentes contextos políticos e sociais e são assim transmitidos para toda coletividade (JELIN; 
LANGLAND, 2003). A memória e suas significações depositadas nos lugares tratam-se, portanto, de uma forma de "rememoração ativa" (HUYSSEN, 2000, p. 67), modo de construção crítica da memória e de democratização local de tais políticas públicas.

Nesse sentido, depositada nos lugares, a memória vincula-se aos conceitos de arquitetura e patrimônio, que passaram por consideráveis transformações nos últimos dois séculos, quando se verifica uma mudança na forma como o tempo é percebido pelas sociedades humanas, na medida em que se intensifica a aceleração do desenvolvimento técnico. François Hartog (2013) identifica estas alterações no tempo, apresentando os regimes de historicidade predominantes em determinados períodos históricos que, em consequência, agem diretamente naquilo que definimos como patrimônio. No pensamento de John Ruskin (1849), teórico fundamental ao conceito de patrimônio, a aceleração do tempo, percebida com a crescente industrialização e com a radical transformação das cidades, representava a desintegração da história e da cultura. Esta aceleração do tempo ameaçava a história e a memória pelo apagamento ou pelo risco de falseamento, refletido na própria intenção de restauro do patrimônio.

$\mathrm{Na}$ América Latina, as formulações acerca do patrimônio enfrentaram o dilema da inserção da cultura local no esquema universal moderno, deparando-se, porém, com o descompasso em relação à periodização estabelecida pela historiografia europeia (WAISMAN, 2013). Por exemplo, no Brasil, a criação do Serviço do Patrimônio Histórico e Artístico Nacional (SPHAN), obra dos intelectuais modernistas no seio do Estado Novo, esteve alicerçada no esforço de formação de uma cultura nacional, nos moldes da periodização da arte europeia, que não se restringiu à inserção, mas constituiu um esforço de superação, de retorno ao passado colonial para a construção de uma modernidade nacional própria, capaz de amalgamar tradicional e moderno. 
Estes apontamentos introduzem elementos básicos da noção de patrimônio e do seu lugar nas sociedades latino-americanas, no processo de modernização entre os séculos XIX e XX. Os objetos propostos para este artigo, três lugares de memória das ditaduras latino-americanas, estão contemplados como patrimônio ao mesmo tempo em que envolvem outros elementos relacionados à memória, que os complexificam. Isto é, como patrimônio, estão inscritos nas questões sobre as teorias de restauro e preservação, embora seu valor histórico esteja apoiado na sua dimensão simbólica como lugares de memória das ditaduras.

Os três edifícios, que materializam e guardam esses lugares, apresentam, quanto ao aspecto formal e material, duas características determinantes: dois deles, a ex-ESMA em Buenos Aires e o Memorial da Resistência em São Paulo, estão instalados em edifícios do início do século XX que, originalmente, abrigavam usos distintos do atual; por sua vez, o Museu da Memória e dos Direitos Humanos, em Santiago, está instalado em um edifício de arquitetura contemporânea, dedicado à preservação da memória da ditadura chilena, pensado e construído exclusivamente para esta finalidade.

Desse modo, nos casos dos lugares selecionados de Argentina e Brasil, a sobreposição das camadas históricas, como um palimpsesto, se apresenta de forma decisiva no edifício como patrimônio. Nesse ponto, somam-se as questões de sua preservação e conservação. No edifício da ex-ESMA são ainda mais decisivas, na medida em que as alterações foram realizadas pelos agentes do Estado, de forma a organizar os espaços de repressão ou encobrir estas práticas. O caso do Chile constitui exemplo distinto, porém, extremamente interessante para se pensar o modo através do qual a sociedade atuou na preservação de sua memória, ao instituir um espaço simbólico e representativo.

Estas arquiteturas, alçadas à patrimônio pela sua relevância histórica e pela sua dimensão de representação da memória coletiva, estão 
marcadas por uma especificidade que as diferem de outros patrimônios culturais. São espaços de disputa em torno da memória, que convivem com o risco da falsificação histórica e do apagamento da memória daqueles que sofreram a violência do Estado em um "momento do perigo", como se refere Walter Benjamin em sua tese VI sobre o conceito de história, diante do recrudescimento do nazismo:

O perigo ameaça tanto a existência da tradição como os que a recebem. Para ambos, o perigo é o mesmo: entregar-se às classes dominantes, como seu instrumento. Em cada época é preciso arrancar a tradição ao conformismo, que quer apoderar-se dela. Pois o Messias não vem apenas como salvador; ele vem também como o vencedor do Anticristo. O dom de despertar no passado as centelhas da esperança é privilégio exclusivo do historiador convencido de que também os mortos não estarão em segurança se o inimigo vencer. E esse inimigo não tem cessado de vencer. (BENJAMIN, 1987, p.224-225)

\section{TRÊS LUGARES DE MEMÓRIA POLÍTICA}

Neste item serão descritos e analisados comparativamente três lugares de memória, objetos deste estudo. Acredita-se que esta análise poderá contribuir para enriquecer a discussão conceitual sobre o tema lugares de memória na América Latina e aprofundar a compreensão de fenômenos sociais contemporâneos complexos (YIN, 2001). Com base nas análises dos históricos de patrimonialização desses bens, pretende-se compreender as inscrições de sentido depositadas e transmitidas pela arquitetura e pelas formas de preservação adotadas nestes dispositivos de memória social.

\subsection{O MODELO EX-ESMA}

O Espacio Memoria y Derechos Humanos, criado oficialmente em 24 março de 2004 (28 aniversário do golpe de Estado na Argentina), abrigou, 
anteriormente, a Escuela de Mecánica de la Armada. Este estabelecimento foi utilizado como o principal aparato do plano sistemático de sequestro, detenção clandestina, tortura e extermínio de opositores da última ditadura civil-militar argentina ${ }^{3}$. Símbolo do terrorismo de Estado, foi transformado em um lugar de memória emblemático para toda América Latina, modelo e referência internacional em política pública de memória e educação em direitos humanos. 0 espaço recebe mais de 200 mil visitantes anualmente (ARGENTINA, 2015).

Durante a ditadura, que vigorou entre 1976 e 1983, estima-se que cerca de cinco mil pessoas desapareceram em suas dependências e ao menos 34 recém-nascidos foram subtraídos da maternidade clandestina que funcionava no local. A preservação do complexo de ruas e edifícios, de 17 hectares, situado na Av. del Libertador, endereço movimentado na zona norte da capital Buenos Aires, deu ensejo e impulsionou a "megacausa ESMA", na qual foram condenados, ao todo, 51 agentes estatais por tortura, genocídio e outros crimes contra os direitos humanos (ARGENTINA, 2015).

Imagem 1 - Fachada da ESMA

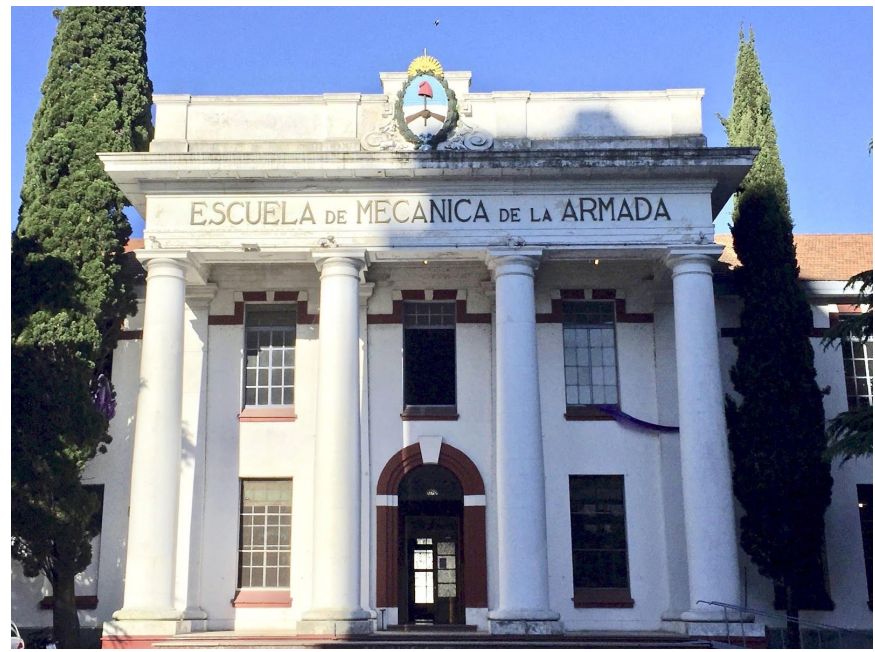

Fonte: acervo pessoal do autor, 2018.

\footnotetext{
${ }^{3}$ A denominada última ditadura militar argentina refere-se à ditadura civil-militar instaurada naquele país entre 1976 e 1983, que teve início com o golpe de Estado de 24 de março de 1976, contra o governo da então presidenta da República María Estela Martínez de Perón, também conhecida como Isabelita Perón. Durante o autodenominado "Processo de Reorganização Nacional", a Argentina foi presidida pelos ditadores militares Jorge Rafael Videla (1976-1981), Roberto Eduardo Viola (1981), Leopoldo Galtieri (1981-1982) e Reynaldo Bignone (1982-1983). Estima-se que mais de 30 mil pessoas tenham sido mortas ou desaparecidas nesse período.
} 
Os primeiros edifícios da ESMA foram construídos em 1924, como sede de uma academia militar da Marinha argentina. Depois de 1976, foi, ao mesmo tempo, instituição de ensino militar, centro clandestino de detenção (CCD) e centro de operações do denominado Grupo de Tareas 3.3.2 (GT 3.3.2). Esse organismo de terrorismo estatal atuou principalmente na desarticulação de organizações populares. A ESMA serviu, também, como CCD para a Aeronáutica, a Prefeitura e o Serviço de Inteligência Naval, de onde saíam os chamados "voos da morte", com a finalidade de fazer desaparecer pessoas sequestradas por motivos políticos (NOVARO; PALERMO, 2007).

Em 1998, sob o governo do presidente Carlos Menem, foi determinada a desocupação da ESMA e sua demolição para dar lugar a um parque público e a um monumento pela reconciliação nacional. Porém, essa medida foi barrada por ações dos familiares das vítimas e de organizações da sociedade civil. O ato do presidente Menem promoveu um amplo debate sobre o tema na sociedade argentina. Nesse processo, a Justiça Federal considerou o complexo como uma testemunha da verdade e uma prova judicial dos horrores perpetrados no passado recente do país (ARGENTINA, 2015). Contudo, somente em 2004, sob o governo do presidente Néstor Kirchner, o complexo da ex-ESMA foi declarado patrimônio nacional, após um longo embate entre as esferas federal e municipal. Prevaleceu a intenção social de preservar o local por seu valor histórico e simbólico. Esse fato expressa a consolidação de uma cultura política democrática que, na sequência, submeteu torturadores e demais agentes de Estado, responsáveis por crimes contra os direitos humanos, a processos judiciais, tendo sido muitos deles condenados à prisão perpétua (WINN, 2014).

Os edifícios da antiga ESMA foram desocupados em novembro de 2007, com a finalidade de destiná-los inteiramente à promoção e defesa dos direitos humanos. Hoje, por exemplo, o espaço abriga o Museo Sitio de Memoria ESMA, inaugurado em 2015, no antigo prédio do cassino dos 
oficiais. A revitalização deste imóvel, após ampla pesquisa e com base em testemunhos de sobreviventes, procurou resgatar os traços do passado, como forma de informar e conscientizar a sociedade (NEVES, 2014).

Uma vez que a arquitetura aparece como algo não estático, mas composto por camadas, que vão se sobrepondo ao edifício ao longo de seu processo histórico, o pressuposto que orientou a preservação dos edifícios da antiga ESMA acabou por expor uma destas camadas da história argentina. Constituiu um modo de manutenção da memória dos presos políticos, ampliou a importância do edifício para além do patrimônio histórico e resgatou o seu aspecto imaterial, representado pela construção crítica da memória coletiva.

\subsection{MEMORIAL DA RESISTÊNCIA E AS DISPUTAS PELA MEMÓRIA E PELA CIDADE}

O Memorial da Resistência de São Paulo foi inaugurado em 2008. Ocupa parte do edifício histórico localizado no Largo General Osório, com frente para a rua Mauá, entre os edifícios da Estação da Luz e da Estação Júlio Prestes, no centro histórico de São Paulo. Atua na preservação da memória da ditadura civil-militar brasileira e conserva parte dos espaços do edifício, antes destinados à detenção de presos políticos. O Memorial divide o Espaço com a Estação Pinacoteca do Estado de São Paulo. Esta ocupa o primeiro andar da edificação, enquanto o Memorial da Resistência encontra-se no térreo e no terceiro andar.

O edifício é um dos exemplares da arquitetura de matriz eclética projetado pelo arquiteto Ramos de Azevedo, que teve ampla e destacada atuação durante o processo de urbanização da cidade, entre o final do século XIX e as primeiras décadas do século XX. O Escritório Técnico Ramos de Azevedo atuou projetando e construindo edifícios exemplares da cidade 
neste período ${ }^{4}$, imprimindo uma imagem moderna à capital paulista que, ao menos até a Primeira República, se encontrava à margem dos centros de maior importância do país. ${ }^{5}$

Neste processo de modernização urbana, o edifício que hoje abriga o Memorial da Resistência recebeu, originalmente, os escritórios administrativos da Estrada de Ferro Sorocabana ${ }^{6}$. Estes usos permaneceram até o ano de 1938. A partir de 1940, o Departamento Estadual de Ordem Política e Social de São Paulo (DEOPS) foi instalado no local, onde permaneceu até 1983, quando foi extinto no processo de redemocratização ${ }^{7}$. A partir de 1983 recebeu outros usos vinculados aos órgãos públicos, tendo sido tombado, na esfera estadual, pelo Conselho de Defesa do Patrimônio Histórico, Arqueológico, Artístico e Turístico (COONDEPHAAT), em 1999.

Imagem 2 - Fachada do Memorial da Resistência

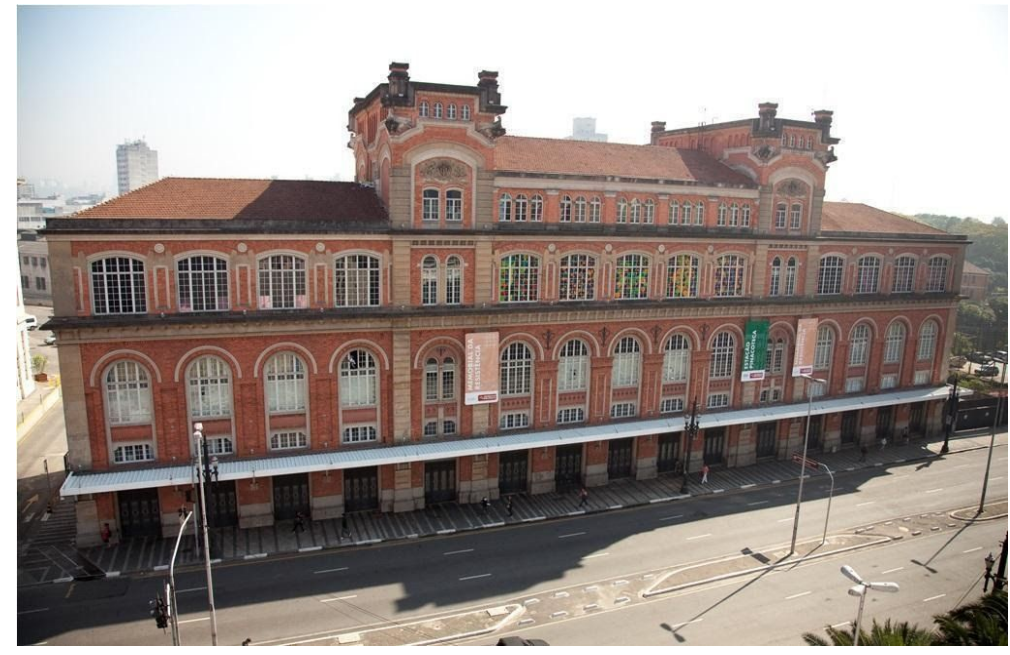

Fonte: (MEMORIAL DA RESISTÊNCIA DE SÃO PAULO, 2020)

\footnotetext{
${ }^{4}$ Entre os edifícios projetados por Ramos de Azevedo na cidade de São Paulo encontram-se, por exemplo, a Faculdade de Medicina da Universidade de São Paulo (USP), o Mercado Municipal e o Teatro Municipal, além da própria Pinacoteca do Estado de São Paulo, localizada na mesma região do Memorial da Resistência.

${ }^{5}$ Segundo Carlos Lemos (1987) o ecletismo foi sinônimo de progresso econômico inaugurado pelo café na cidade de São Paulo.

${ }^{6}$ Situava-se entre duas estações ferroviárias, as atuais estações de metrô e trens metropolitanos de São Paulo. Além dos escritórios, o prédio projetado por Ramos de Azevedo e inaugurado em 1914, abrigava armazéns para os itens transportados através da ferrovia.

${ }^{7}$ Durante a maior parte do período ditatorial, o DEOPS atuou como polícia política do estado de São Paulo, cujo edifício funcionou como centro de repressão, controle social e detenção de presos políticos.
} 
O processo de tombamento, aberto em 1976, durou mais de 20 anos. Sua patrimonialização, mesmo que ocorrida em período democrático, se realizou à margem de uma participação social mais ampla, privilegiando o histórico arquitetônico associado à Estrada de Ferro Sorocabana e à modernização da cidade. As reformas realizadas no edifício ocorreram em tempos de democracia, com o nítido intuito de ocultação da história do período ditatorial (NEVES, 2014). A carceragem do DEOPS, onde diversos presos políticos foram detidos e torturados, foi quase totalmente descaracterizada entre a passagem dos anos 1990 e 2000 (SÃO PAULO, 2017). A restauração foi concluída em 2002 e o prédio recebeu usos diversos, enquanto centro expositivo.

A partir de 2004, quando o edifício passou a ser de responsabilidade da Pinacoteca, o Fórum de Ex-Presos e Perseguidos Políticos, em conjunto com outras organizações da sociedade civil, como a Comissão de Familiares e Presos Políticos, passaram a discutir e a pressionar para sua ocupação como lugar de memória crítico à repressão e ao terrorismo de Estado. O espaço foi reaberto com a denominação Memorial da Resistência, em 2008. Com base em ampla pesquisa e testemunhos de ex-presos políticos detidos no local, quatro celas da carceragem foram reconstituídas, em formato similar ao de period rooms, onde inscrições nas paredes foram refeitas pelos ex-presos em um ato simbólico de inauguração. A intervenção museológica foi uma tentativa de minimizar os danos causados pelo apagamento dos rastros traumáticos do passado (NEVES, 2014). Atualmente, o Memorial da Resistência de São Paulo conta com um centro de referência para pesquisa, atua na salvaguarda de acervo custodiado, possui auditório, área de exposição permanente, área para exposições temporárias e desempenha ações educativas-culturais, com enfoque temático sobre a resistência, controle e repressão política, não exclusivamente sobre o período da ditadura civil-militar brasileira.

A região do bairro da Luz, onde se encontra o Memorial da Resistência, no centro de São Paulo, tem recebido nas últimas duas 
décadas alguns projetos significativos de revitalização urbana. ○ mais conhecido deles foi lançado em 2005 pela Prefeitura, sob o nome "Projeto Nova Luz", propondo a requalificação dos espaços urbanos através da construção de novos equipamentos e de parcerias com empresas privadas por meio de uma concessão urbanística. Uma das propostas consistia na construção de um complexo cultural cujo programa comportava espetáculos musicais e de dança, projetado pelo escritório de arquitetura suiço Herzog e De Meuron, mundialmente reconhecido e vencedor do Prêmio Pritzker em 2001.

Este episódio colocou em evidência as intensas disputas e interesses diante do potencial imobiliário do centro da cidade. O projeto enfrentou a resistência de movimentos sociais, moradores e comerciantes, que temiam a escalada de um processo de gentrificação na região da Luz e da Santa Ifigênia (AMORIM, 2016, p.150). No local, as pressões imobiliárias já se manifestavam através das recorrentes ações policiais, que por anos atuaram de forma ostensiva para a expulsão de pessoas em situação de rua, expostas ao tráfico de drogas, que se encontravam nas proximidades.

Na última década, o acirramento dos embates políticos no Brasil se desdobrou para o campo da memória da ditadura civil-militar. Grupos de extrema-direita que se opunham às atividades da Comissão Nacional da Verdade, ${ }^{8}$ negavam ou até exaltavam as violências praticadas pelo regime. Em 2012, no limiar deste período, durante a rápida transformação da conjuntura política no país, um outro projeto foi proposto para a região do bairro da Luz, denominado Memorial da Democracia. Foi desenvolvido pelo escritório paulista Brasil Arquitetura, dos arquitetos Marcelo Ferraz e Francisco Fanucci, reconhecidos pela atuação em projetos de museus e de preservação do patrimônio. Embora não construído, o Memorial da Democracia se insere nesse ambiente de disputa pela memória. Localizado na mesma rua Mauá, seria um complemento ao atual Memorial da

\footnotetext{
${ }^{8}$ A Comissão Nacional da Verdade foi criada pela Lei 12528/2011, para apurar as violações de Direitos Humanos ocorridas entre 18 de setembro de 1946 e 5 de outubro de 1988 no Brasil.
} 
Resistência, contribuindo, para além do novo espaço, como marco da memória da ditadura na paisagem do centro da cidade.

A região do bairro da Luz, que tem passado por diversas tentativas de reformulação, permanece como local de conflitos urbanos, de luta por moradia em oposição à crescente gentrificação, evidenciada através dos grandes projetos culturais encomendados a arquitetos de renome internacional. O Memorial da Democracia, por sua vez, edifício proposto em 2012 e não construído, marca a reviravolta política dos últimos anos no país. O Memorial da Resistência representa uma conquista pela preservação da memória política da ditadura, em meio às disputas pela cidade que se travam na região da Luz, local marcado pelos conflitos sociais e pela repressão na cidade de São Paulo.

\subsection{MUSEO DE LA MEMORIA Y LOS DERECHOS HUMANOS: ARQUITETURA CONTEMPORÂNEA LATINO-AMERICANA}

O Museu da Memória e dos Direitos Humanos, de Santiago, no Chile, criado para preservar a história das vítimas da ditadura civil-militar chilena e manter a defesa dos direitos humanos no país, conserva documentos que remetem ao período de 1973 até 1990. A construção do Museu, como lugar de memória, resultou de um concurso de abrangência internacional, durante o governo da Presidente Michelle Bachelet. Concursos de projeto de arquitetura são, por sua vez, formatos profícuos ao confronto de idéias que, frequentemente, resultam casos paradigmáticos para a história da arquitetura, capazes de estimular a crítica e o debate, propor novos rumos e gestar novos personagens ou uma nova geração de projetistas. São representativos de um momento histórico, da cultura de uma sociedade, das crises e das possibilidades de superação de uma hegemonia arquitetônica. 
O concurso para o Museu teve mais de 50 propostas submetidas e 5 projetos premiados. Chama a atenção, entre os projetos escolhidos, a predominância de arquitetos de dois países: o próprio Chile, com escritórios sediados em Santiago, alcançando o segundo e terceiro lugares, além da primeira menção honrosa; e Brasil, com dois escritórios de São Paulo, que alcançaram o primeiro lugar e a segunda menção honrosa (PORTAL VITRUVIUS, 2007). A prevalência destes dois países aparece, neste caso, como possibilidade de compreensão das duas culturas arquitetônicas naquele momento. ${ }^{9}$

O projeto vencedor para o edifício inaugurado em 2010 é de autoria do grupo de arquitetura Estudio America, sediado na cidade de São Paulo pelos arquitetos e professores de arquitetura Mario Figueroa, Lucas Fehr e Carlos Dias, em conjunto com sua equipe. O edifício adota, de forma marcante, um elemento que aparece, também, nos demais projetos contemplados pelo concurso, que consiste na elaboração de uma praça que antecede a entrada no edifício evocando seu caráter cívico e que aparece, em maior ou menor grau, enterrada ou rebaixada a partir da cota da rua.

\footnotetext{
${ }^{9}$ Não se tem, neste texto, o objetivo de aprofundar a análise dos projetos premiados no concurso. O foco da abordagem é a intenção dada ao edifício como lugar de memória e sua relação com os seus pares latino-americanos. Limitamo-nos à apresentação do projeto construído, sua dimensão como lugar de memória, seus vínculos com o momento e a tradição arquitetônica dos dois países e sua inserção na cultura arquitetônica latinoamericana.
} 
Imagem 3 - Fachada iluminada do Museu da Memória e dos Direitos Humanos

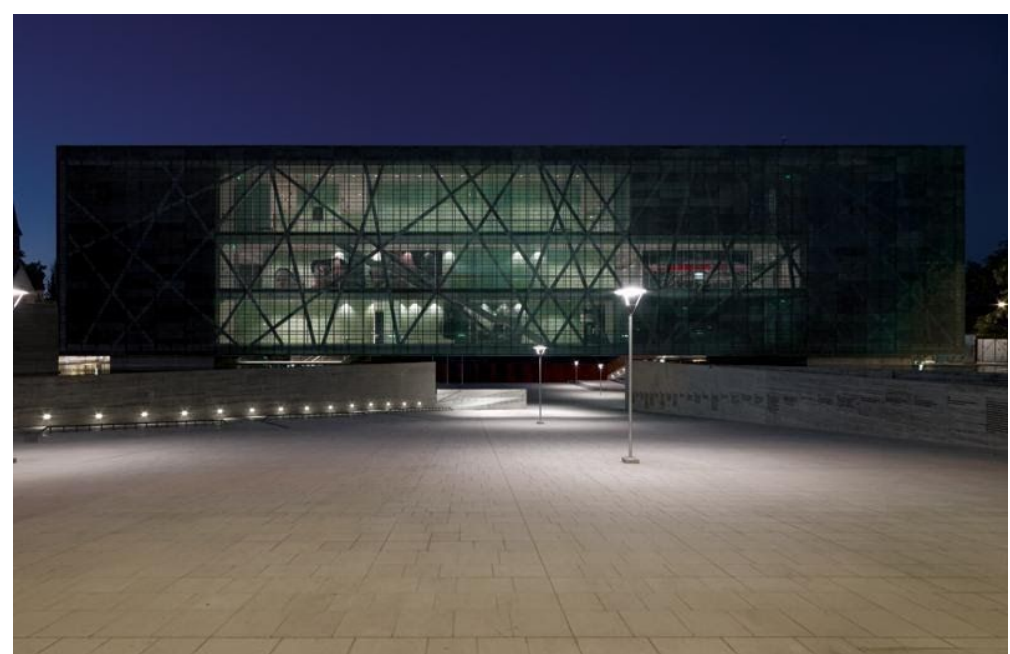

Fonte: (MUSEU DA MEMÓRIA E DOS DIREITOS HUMANOS, 2010)

Este artifício determinado pelo ato de rebaixar certo patamar no terreno, enterrar parte do programa, movimentando as cotas e trabalhando com níveis distintos de modo a criar espaços públicos ou semipúblicos, é contemplado por um segundo recurso, uma estrutura, que pode ou não receber parte do programa e funciona como uma grande cobertura para a primeira. Esta descrição pode ser útil ao Museu da Memória, mas poderia servir a outros inúmeros edifícios icônicos da arquitetura brasileira:

A imagem mais forte do museu, neste sentido, é a de uma caixa de cobre que flutua sobre o vazio. Semelhanças com referências tão díspares como o MASP, de Lina Bo Bardi, ou o Mube, de Mendes da Rocha, são evidentes. O museu propriamente dito fica dentro desta caixa. São quatro andares constituídos como um grande ambiente sem sequência expositiva linear. (SERAPIÃO, 2010)

Aos exemplos do Museu Brasileiro da Escultura (MUBE), de Paulo Mendes da Rocha e do Museu de Artes de São Paulo (MASP), de Lina Bo Bardi, poderiam ser acrescidos outros edifícios que adotam a cobertura e o espaço público ou semipúblico como elemento primordial: o edifício da Faculdade de Arquitetura e Urbanismo da USP; o Centro Cultural São Paulo; a Praça das Artes ou o Instituto Moreira Salles mais recentemente, 
todos na cidade de São Paulo e o Pavilhão Brasileiro na Expo 70 em Osaka. Mas, também, o Museu de Arte Moderna e o Palácio Capanema, no Rio de Janeiro; o Museu de Arte Contemporânea de Niterói; o edifício da Faculdade de Arquitetura e Urbanismo da Universidade Federal da Bahia, em Salvador; o Edifício Central e da Reitoria da Universidade de Brasília e, por que não, a própria Catedral de Brasília, na qual a ideia de cobertura é fundamental.

Esta ideia é continuamente evocada pela literatura (SERAPIÃO, 2010), quando se trata do fenômeno do modernismo no Brasil, geralmente associada a uma tradição paulista. Temos o exemplo recente da exposição "Infinito Vão", 10 realizada em Matosinhos, Portugal, sobre a arquitetura brasileira (FERRAZ, 2019), que explora este aspecto, cujo o Museu da Memória de Santiago aparece como exemplo recente de sua permanência contemporânea. A referência a uma técnica recorrente na cultura arquitetônica brasileira é lembrada no memorial do projeto pelos autores, destacando-se o arquiteto Mario Figueroa, nascido no Chile, mas radicado no Brasil, onde fez toda a sua formação e construiu sua trajetória profissional:

\begin{abstract}
A memória evidenciada, emergente, que flutua, suavemente elevada. Uma arca, onde se pode depositar todas as reminiscências da história chilena. [...] A estrutura da barra é integra, uma, e sem concessões evidencia a elevação da memória. Teremos uma materialidade etérea, qual pedra de Magritte. Assim, uma composição de treliças metálicas, um túnel, vence todo o vão, com a carga descarregando em quatro apoios nos limites. Nelas vinculadas, as caixas de exposição, translúcidas, que protegidas pelo afastamento das extremidades, garantem a controlada iluminação do Museu. (PORTAL VITRUVIUS, 2007)
\end{abstract}

A descrição de um volume elevado que "flutua" e vence um vão é acompanhada da menção aos materiais translúcidos, que remetem à contemporaneidade. Uma possível atualização da tradição arquitetônica referida, diante da condição globalizada da arquitetura. A utilização da

\footnotetext{
10 Exposição "Infinito Vão - 90 anos de arquitetura brasileira", Casa da Arquitectura - Centro Português de Arquitectura, Matosinhos, 28 de setembro de 2018 a 28 de abril de 2019. Comissariado geral Nuno Sampaio. Curadoria Fernando Serapião e Guilherme Wisnik.
} 
materialidade translúcida da caixa revelando o seu interior, mesmo que parcialmente, aparece como recurso simbólico que remete a uma dimensão cívica da arquitetura (FOSTER, 2017, p. 49-50), reforçada pela grande praça pública. Embora potente, operar este recurso simbólico acarreta o risco de surtir o efeito contrário, de tornar-se um gesto gratuito de promoção da arquitetura como imagem. Nesse sentido, quanto ao uso indiscriminado dos elementos translúcidos, algo recorrente na arquitetura contemporânea, Hal Foster alerta:

O que está implícito nesta arquitetura da leveza é que a transparência, desejada ou não, é impossível num mundo entregue à forma-mercadoria - ou seja, onde o mecanismo da maioria das coisas constitui outras tantas caixas pretas. (FOSTER, 2017, p.152)

Imagem 4 - Imagem aérea do Museu da Memória e dos Direitos Humanos em Santiago, Chile.

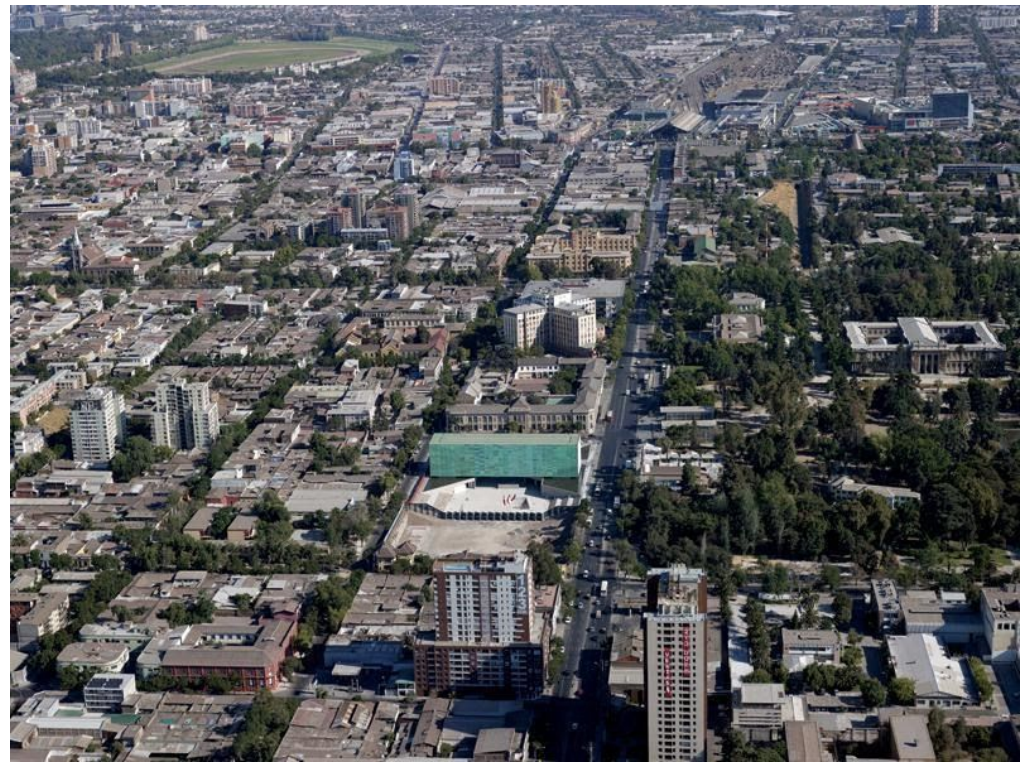

Fonte: (MUSEU DA MEMÓRIA E DOS DIREITOS HUMANOS, 2020)

Pedro Arantes (2010, p.72) reitera a tendência ao uso de materiais translúcidos entre os arquitetos do chamado star system, que obstrui a percepção do interior dos edifícios e da estrutura que os sustenta, ofuscando aquilo que os arquitetos modernos pretenderam revelar como intenção de uma postura ética. Neste ponto, tanto Arantes (2010), quanto Foster (2017), tratam do efeito dos novos materiais para a espetacularização dos edifícios e de sua sujeição à imagem na cultura contemporânea, 
atravessada pelo consumo. Seus objetos de análise são os edifícios construídos nas últimas décadas nos centros avançados do capitalismo, por arquitetos, principalmente europeus, que ganharam projeção global.

O Museu da Memória e dos Direitos Humanos do Chile, sem dúvida, dialoga com esta conjuntura, impossibilitado de se desvencilhar destas imagens. De outra forma, ao aderir à uma cultura arquitetônica latino-americana, como costuma indicar a literatura quanto à sua filiação ao modernismo brasileiro, o edifício parece dar sobrevida a uma linguagem que parecia banalizada no Brasil desde a desagregação do moderno. Entretanto, mais do que a associação automática aos grandes vãos, sua potência parece estar em seu poder de síntese simbólica, capaz de sintetizar memória e caráter cívico num único elemento, como em alguns edifícios de Brasília.

\subsection{ANÁlise dos LUGARES DE MEMÓRIA EM PERSPECTIVA COMPARADA}

Para uma análise, em perspectiva comparada, quanto aos três lugares de memória referidos acima, destacam-se alguns pontos, considerados principais. Foram selecionados três lugares com trajetórias especialmente distintas. Porém, da mesma forma, são lugares socialmente marcados, utilizados como veículos ou suportes materiais de memória, com a finalidade de desenvolver a rememoração ativa, conscientizadora e democrática sobre os horrores das ditaduras civis-militares em seus países. A ex-ESMA, o antigo DEOPS e o museu da memória chileno foram inaugurados em 2004, 2008 e 2010, respectivamente. Isto é, as iniciativas de constituição como lugares de memória surgem no seio da sociedade civil e, posteriormente, se consolidam como políticas públicas de construção da memória, na primeira década do século XXI, quando ocorreu 
o chamado boom de memória das ditaduras latino-americanas (WINN, 2014).

Portanto, temos três exemplos cujos percursos de inscrição de sentido são diferentes, mas, igualmente, representam êxitos nas lutas por memória. O primeiro, a ex-ESMA, em Buenos Aires, foi preservado. 0 segundo, o antigo DEOPS, em São Paulo, de certa forma, foi reconstituído. O terceiro caso, o museu da memória, no Chile, foi construído, a partir de elementos da arquitetura modernista, exclusivamente para abrigar a memória coletiva. Muito embora, nos dois primeiros casos de lugares tenham ocorridos graves violações dos direitos humanos, o que não ocorreu no caso chileno selecionado, os três exemplos são revestidos de simbologia, detêm a intencionalidade por parte da sociedade e, justamente, por isso, são considerados lugares de memória emblemáticos.

Com relação à patrimonialização desses bens, a ex-ESMA, em Buenos Aires, seria demolida para se tornar um parque público. Esse projeto foi barrado pela mobilização popular. O seu reconhecimento, enquanto bem de interesse público e com valor histórico nacional, se deu pelo valor simbólico, inclusive, através de via judicial. A sua preservação serviu como base para a persecução penal de torturadores e, também por isso, se tornou um modelo de referência em toda América Latina. O complexo de prédios sofreu alguma descaracterização durante o período ditatorial argentino, para ocultar os crimes praticados em seu interior. Mesmo assim, suas características, enquanto centro clandestino de detenção, foram preservadas e abertas à visitação pública.

No caso do antigo DEOPS, em São Paulo, sua patrimonialização, somente na esfera estadual, ocorreu por parte do poder público, sem participação popular direta, e se deu pelo seu valor arquitetônico, pertencente ao ecletismo paulista, inserido em um processo maior de revitalização de uma área específica da cidade. As descaracterizações ocorridas no imóvel, para apagar os vestígios dos crimes da ditadura, 
curiosamente, ocorreram sob regime democrático e levaram à total destruição desses elementos. Por isso, posteriormente, uma pequena parte da carceragem foi reconstruída e inaugurada em ato simbólico com a presença de ex-presos políticos.

O exemplo do Chile, por sua vez, nos remete a um projeto arrojado, nos moldes do que também se fez, alguns anos depois, em 2012, no centro de São Paulo, com o projeto não construído do Memorial da Democracia. Edifícios contemporâneos, de arquitetura potente, designados como espaços de guarda da memória e marcos urbanos. O desafio colocado aos arquitetos para este tipo de programa é pautado pela capacidade de conferir ao espaço a transmissão da memória, sem recorrer de forma indiscriminada à promoção do edifício como imagem. Num segundo aspecto, que distingue o Museu da Memória de Santiago dos seus pares localizados em Buenos Aires e São Paulo, o edifício é capaz de projetar esta memória para a paisagem da cidade, o que expande a sua dimensão simbólica para além dos seus espaços expositivos internos. Um lugar de memória capaz de comunicar, através de seu edifício, a memória coletiva de um episódio traumático da história do país.

Assim, quanto à origem destes três lugares de memória latino-americanos, há algo que lhes é comum: são produtos de lutas políticas, de batalhas por memória, em uma conjuntura democrática, na qual é retomada a memória de um passado recente e traumático, representado pelas ditaduras civis-militares em que estiveram submetidos os três países. Este resgate é resultado da mobilização social. Muito embora tenham percursos completamente diferentes, nos três dispositivos mencionados, ocorreu, em algum momento, a intenção de parcelas da sociedade em constituir esses espaços como depositários da memória coletiva, com a finalidade precípua de conscientização. Em todos eles estão depositadas inscrições de sentido, que são transmitidas ao público por meio da arquitetura, das ações educativas, dos acervos e, também, de sua 
própria preservação. Em resumo e esquematicamente, a comparação entre os três casos pode ser visualizada no quadro 1 a seguir:

Quadro 1 - Quadro comparativo

\begin{tabular}{|c|c|c|c|}
\hline & $\begin{array}{l}\text { Espacio Memoria y } \\
\text { Derechos Humanos } \\
\text { (Ex-ESMA) }\end{array}$ & $\begin{array}{l}\text { Memorial da } \\
\text { Resistência }\end{array}$ & $\begin{array}{l}\text { Museo de la } \\
\text { Memoria y los } \\
\text { Derechos Humanos }\end{array}$ \\
\hline $\begin{array}{l}\text { Período ou ano de } \\
\text { construção do edifício }\end{array}$ & 1924 & 1910-1914 & $2007-2010$ \\
\hline $\begin{array}{l}\text { Ano de } \\
\text { patrimonialização }\end{array}$ & 2004 & 1999 & - \\
\hline $\begin{array}{l}\text { Esfera administrativa } \\
\text { de patrimonialização }\end{array}$ & federal & estadual & - \\
\hline $\begin{array}{l}\text { Participação popular } \\
\text { no processo de } \\
\text { patrimonialização }\end{array}$ & $\operatorname{sim}$ & não & - \\
\hline $\begin{array}{l}\text { Ensejo do processo de } \\
\text { patrimonialização }\end{array}$ & $\begin{array}{l}\text { valor } \\
\text { histórico/simbólico }\end{array}$ & valor arquitetônico & - \\
\hline $\begin{array}{l}\text { Ano de } \\
\text { fundação/criação do } \\
\text { lugar de memória }\end{array}$ & 2004 & 2008 & 2010 \\
\hline $\begin{array}{l}\text { Presidente do } \\
\text { governo vigente à } \\
\text { época da inauguração }\end{array}$ & Néstor Kirchner & $\begin{array}{l}\text { Luiz Inácio Lula da } \\
\text { Silva }\end{array}$ & Michelle Bachelet \\
\hline $\begin{array}{l}\text { Participação popular } \\
\text { no processo de } \\
\text { criação do lugar de } \\
\text { memória }\end{array}$ & $\operatorname{sim}$ & $\operatorname{sim}$ & $\operatorname{sim}$ \\
\hline $\begin{array}{l}\text { Espaço expositivo } \\
\text { para construção da } \\
\text { memória }\end{array}$ & preservado & reconstituído & construído \\
\hline $\begin{array}{l}\text { Esfera administrativa } \\
\text { responsável }\end{array}$ & federal & estadual & federal \\
\hline $\begin{array}{l}\text { Aberto à visitação } \\
\text { pública }\end{array}$ & $\operatorname{sim}$ & $\operatorname{sim}$ & $\operatorname{sim}$ \\
\hline
\end{tabular}

Fonte: Elaboração dos autores

\section{CONSIDERAÇÕES FINAIS}

Os três lugares se inserem em um movimento de resgate da história, em face aos crimes cometidos pelas ditaduras civis-militares contra os direitos humanos. Isto é possível em um momento de estabilização da democracia após décadas de ditadura, coincidindo com a existência de governos progressistas nesses países. No Chile, o início da concepção do 
projeto do museu ocorreu em paralelo com os governos de Ricardo Lagos Escobar (2000-2006) e Michelle Bachelet (2006-2010 e 2014-2018), ambos do Partido Socialista. Movimento parecido ocorreu, também, na Argentina e no Brasil, quando ocupavam a presidência dos respectivos países Nestor Kirchner (2003-2007), do Partido Justicialista, e Luiz Inácio Lula da Silva (2002-2006 e 2006-2010) do Partido dos Trabalhadores. Nos três casos, os presidentes sofreram algum tipo de perseguição política ou foram presos durante os regimes de exceção.

Conforme o "momento do perigo" referido por Walter Benjamin (1987, p.224), é papel do historiador retomar o passado dos que foram subjugados ou vencidos, contrapondo-se à história apresentada como progresso. Os lugares de memória apresentados neste trabalho retomam uma tradição: manter viva a história que se tentou ocultar com o fim das ditaduras. De diferentes formas, através da preservação e do restauro de elementos que foram apagados, ou da formulação de um novo espaço simbólico, estes lugares reivindicam por meio de suas arquiteturas uma história não linear, que mantém viva a memória coletiva.

\section{AGRADECIMENTOS}

Os autores agradecem, especialmente, à profa. dra. Nair Yumiko Kobashi, do Programa de Pós-graduação em Ciência da Informação da Escola de Comunicações e Artes da Universidade de São Paulo (PPGCI/ECA/USP), pela orientação e à doutoranda em Ciência da Informação (PPGCI/ECA/USP) Mariana Ramos Crivelente por toda ajuda. O primeiro autor agradece também à Coordenação de Aperfeiçoamento de Pessoal de Nível Superior (CAPES), pela bolsa de estudos concedida.

\section{REFERÊNCIAS}

AMORIM, Fernando de Oliveira. Uma experiência de mobilização e resistência dos movimentos sociais no processo de planejamento 
urbano: o Projeto Nova Luz em São Paulo. 2016. Tese (Doutorado em Planejamento Urbano e Regional) - Faculdade de Arquitetura e Urbanismo, Universidade de São Paulo, São Paulo, 2016. doi:10.11606/T.16.2017.tde-19122016-151119.

ARANTES, Pedro Fiori. Arquitetura na era digital-financeira: desenho, canteiro e renda da forma. 2010. Tese (Doutorado em Tecnologia da Arquitetura) - Faculdade de Arquitetura e Urbanismo, Universidade de São Paulo, São Paulo, 2010. doi:10.11606/T.16.2010.tde-01062010-095029.

ARGENTINA. MINISTERIO DE JUSTICIA Y DERECHOS HUMANOS DE LA NACIÓN. Secretaría de Derechos Humanos. Espacios de memoria en la Argentina. Buenos Aires: Ministerio de Justicia y Derechos Humanos de la Nación. Secretaría de Derechos Humanos, 2015.

BENJAMIN, Walter. Magia e técnica, arte e política: ensaios sobre literatura e história da cultura. São Paulo, Brasiliense, 1987.

FERRAZ, Marcelo Carvalho. Arquitetura em vão? Sobre exposição da arquitetura brasileira em Matosinhos, Portugal. Resenhas Online, São Paulo, ano 18, n. 205.04, Vitruvius, jan. 2019. Disponível em: https://www.vitruvius.com.br/revistas/read/resenhasonline/18.205/7231.

Acesso em: 28 maio 2020.

FOSTER, Hal. O complexo arte-arquitetura. São Paulo: Ubu Editora, 2017.

HARTOG, François. Regimes de historicidade: presentismo e experiências do tempo. Belo Horizonte: Autêntica Editora, 2013.

HUYSSEN, Andreas. Seduzidos pela memória: arquitetura, monumentos, mídia. Rio de Janeiro: Aeroplano, 2000.

JELIN, Elizabeth. Los trabajos de la memoria. Madrid: Siglo XXI, 2002.

JELIN, Elizabeth; LANGLAND, Victoria. Monumentos, memoriales y marcas territoriales. Madrid: Siglo XXI, 2003.

LEMOS, Carlos Alberto Cerqueira. O Ecletismo em São Paulo. In: FABRIS, Annateresa (org). Ecletismo na arquitetura brasileira. São Paulo, Nobel, Editora da Universidade de São Paulo, 1987.

MEMORIAL DA RESISTÊNCIA DE SÃO PAULO. Sobre o Memorial da Resistência. Disponível em: http://www.memorialdaresistenciasp.org.br/memorial/default.aspx?mn=4\& $c=83 \& \mathrm{~s}=0 \#$. Acesso em: 30 maio 2020.

MUSEU DA MEMÓRIA E DOS DIREITOS HUMANOS. Museu da Memória/ Estúdio América. $\mathrm{s} / \mathrm{d}$. Disponível em: https://www.archdaily.com.br/br/01-715/museu-da-memoria -estudio-america?ad_medium=gallery. Acesso em: 27 maio 2020. 
MUSEU DA MEMÓRIA E DOS DIREITOS HUMANOS. Museu da Memória + Centro Matucana - Santiago - Chile. 2010. Disponível em: https://concursosdeprojeto.org/2010/05/02/museu-memoria-chile/. Acesso em: 27 maio 2020.

NEVES, Deborah. A persistência do passado: patrimônio e memoriais da ditadura em São Paulo e Buenos Aires. 2014. Dissertação (Mestrado em História Social) - Faculdade de Filosofia, Letras e Ciências Humanas, Universidade de São Paulo, São Paulo, 2014.

NORA, Pierre. Entre Memória e História: a problemática dos lugares. Trad. Yara Aun Khoury. Proj. História, São Paulo, (10), dez. 1993.

NOVARO, Marcos; PALERMO, Vicente. A Ditadura Militar Argentina 1976-1983: do golpe de Estado à restauração democrática. São Paulo: Editora da Universidade de São Paulo, 2007.

PORTAL VITRUVIUS. Concurso de Arquitectura Centro Matucana - Museo de la Memoria. Projetos, São Paulo, ano 07, n. 083.01, Vitruvius, jun. 2007. Disponível https://www.vitruvius.com.br/revistas/read/projetos/07.083/2840. Acesso em 01 de julho de 2020.

RICOEUR, Paul. A memória, a história, o esquecimento. Campinas: Editora da Unicamp, 2018.

RUSKIN, John. The Seven Lamps of Architecture. London: Smith, Elder, 1849.

SÃO PAULO (Brasil). Secretaria Municipal de Direitos Humanos e Cidadania. Memórias resistentes, memórias residentes: lugares de memória da ditadura civil-militar no município de São Paulo. São Paulo: Memorial da Resistência de São Paulo: Associação Pinacoteca Arte e Cultura, 2017.

SERAPIÃO, Fernando. Um museu para a memória chilena. Jornal Folha de São Paulo, São Paulo, 18 de janeiro de 2010. Disponível: https://www1.folha.uol.com.br/fsp/ilustrad/fq1801201017.htm. Acesso em: 28 maio 2020.

WAISMAN, Marina. O interior da história : historiografia arquitetônica para uso de latino-americanos. São Paulo, Perspectiva, 2013.

WINN, Peter. (ed.). No hay mañana sin ayer: batallas por la memoria histórica en el Cono Sur. Santiago: LOM Ediciones, 2014.

YIN, Robert. Estudo de caso: planejamento e métodos. Porto Alegre: Bookman, 2001. 